\title{
Monitoring dynamic stiffness that predicts concrete structure degradation
}

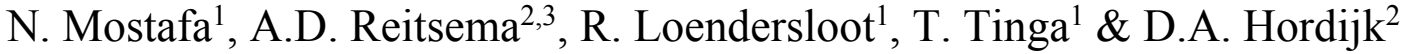

1 University of Twente, the Netherlands

2 Delft University of technology, the Netherlands

3 Heijmans N.V., the Netherlands

\begin{abstract}
This paper presents a series of laboratory experiments on a scaled reinforced concrete bridge deck as well as results of a pilot project on an existing bridge. The ultimate goal is to develop a structural health monitoring system based on evaluation of the dynamic bending stiffness which would be derived from easy to use measurement devices. The experiments are aimed at measuring the deflection for static load, and the dynamic response due to a moving mass, representing a traffic load. The two types of applied sensors are accelerometers and linear variable differential transducer (LVDT). Lab results include dynamic response from uncracked, partial cracked and fully cracked conditions, which influenced the dynamic stiffness. Changes of stiffness therefor is to be believed to be a parameter for crack conditions. The concept has been applied to an existing bridge to prove its value.
\end{abstract}

\section{INTRODUCTION}

In the Netherlands infrastructure has always been important with regard to its status as transport country with Rotterdam as Europe's largest port. There has been a large infrastructural expansion in-between the sixties and eighties (fig.1). Public authorities face a major replacement task given that most of the existing bridges are designed to serve for 50 years. This, combined with a large historical increase in traffic frequency and loads combined with new insights regarding structural behavior, makes that the performance of some existing bridges can be questionable. Still, there isn't an indication of structural failures in the near future, so it is clear that the actual capacity of existing bridges is not directly related to a service life of 50 years the bridges were designed for.

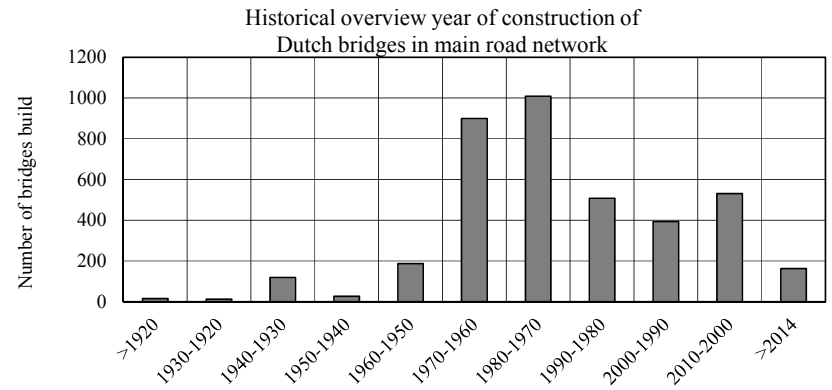

Figure 1. Bridge construction year (RWS, 2015).
Till now, for far most of the existing bridges qualitative and non-continuous methods are used to determine degradation. These methods are not able to give an accurate assessment of the real structural performance of a structure. Therefore, it can be favorable to apply a structural health monitoring (SHM) system on civil structures to conclude whether or not an intervention is mandatory (Cremona 2014). This makes that decisions regarding operating conditions can be made based on quantitative data. In addition to the reevaluation of older existing bridges, SHM can be used to measure the load response of new bridge techniques and/or materials. The purpose of this research is to find out whether it is feasible to assess the structural integrity of a concrete bridge using a limited set of (de)mountable sensors. In this paper results of experiments in a laboratory, and on a railway bridge are presented.

\section{THEORY}

The theory of the SHM method being developed for the use on concrete bridges is based on determining the bending stiffness (EI) over time, which is believed to be a parameter for the global structural integrity of an infrastructural element. Here, measuring deformations and accelerations during a limited time period makes that the response of a structural body under a load can be derived. In order to define the global integrity of a structure its response over time is used 
to calculate the bending stiffness. When comparing the bending stiffness at an measured time period with another measured time period, it can reveal variation which may indicate an increased crack pattern (Reitsema, 2015). When analyzing the variation in bending stiffness over time one can assess structural integrity.

\section{LABORATORY AND PILOT EXPERIMENTS}

In order to investigate the feasibility of the SHM method for concrete bridges multiple laboratory experiments and one pilot project are executed. The laboratory experiments are performed on concrete beams. The purpose of the laboratory experiments is to proof that monitoring the dynamic stiffness enables to detect the degradation of concrete beams. The pilot project on an existing concrete railway bridge is executed to find if loads induced by trains can be used to determine the dynamic bending stiffness and if the monitoring system can be scaled from laboratory to real bridges. For the laboratory experiments different load levels, positions, and travel speeds are used.

An overview of the laboratory test is shown in Table 1. The damage levels that are shown in the final column are related to the amount of cracking that is present. Level 0 is a uncracked beam, level 1 represents a beam that is loaded until the first crack occurs, level 2 is a partially cracked beam, and level 3 is a fully cracked beam. The pilot project is on an existing uncracked pre-stressed concrete railway bridge.

Table 1. Laboratory experiments

\begin{tabular}{lcccc}
\hline \hline Experiment & Load & Load & Speed & Damage \\
\cline { 2 - 5 } No. & $(\mathrm{kg})$ & Place & $(\mathrm{m} / \mathrm{s})$ & level \\
\hline 1.Calibration & $0-50$ & Bearing & - & 0 \\
2.TDB* & 25,50 & Bearing & - & 0 \\
3.Static & $0-80$ & Mid-span & - & 0 \\
4.Impact & - & - & - & 0 \\
5.Static & $0-90$ & Mid-span & - & 1 \\
6.Impact & - & - & - & 1 \\
7.Static & $0-120$ & Mid-span & - & 2 \\
8.Impact & - & - & - & 2 \\
9.Static & $0-180$ & Mid-span & - & 3 \\
10.Impact & - & - & - & 3 \\
11.Moving Load & $10-20-30$ & - & $1,1.5,2$ & 0 \\
12. Moving Load & $10-20-30$ & - & $1,1.5,2$ & 2 \\
13. Moving Load & $10-20-30$ & - & $1,1.5,2$ & 3 \\
\hline *TDB is time dependent behavior of bearing blocks
\end{tabular}

\section{LABORATORY EXPERIMENT SETUP}

The test setup of the laboratory experiment consists of a C35/45 concrete beam with a total length of $2500 \mathrm{~mm}$, a width of $300 \mathrm{~mm}$ and a height of $75 \mathrm{~mm}$ (figure 2). The reinforcement consist of four bars with a diameter of $6 \mathrm{~mm}$ in the centre of the cross section (dashed lines in figure 2). The beam is supported by two cylindrical rubber bearing blocks which are placed $100 \mathrm{~mm}$ from the edge of the beam leaving a total span of $2300 \mathrm{~mm}$. The diameter of the bearing blocks is $85 \mathrm{~mm}$ and the height is $75 \mathrm{~mm}$. Two LVDTs are situated just at the right and the left of the bearing (see figure 3 ).

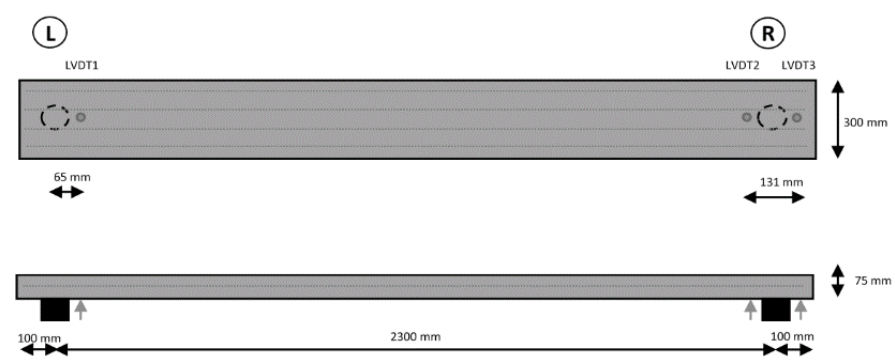

Figure 2. Concrete beam used for laboratory experiments

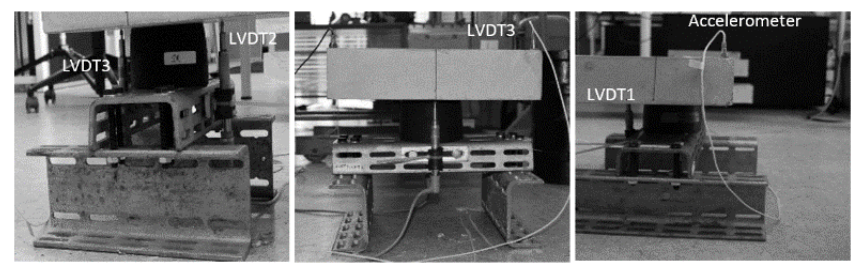

Figure 3. Placement of the LVDTs besides the rubber support

In preparation of the accelerometer measurements, a grid indicating the sensor locations and hitting points was made, thus obtaining an array of simultaneously measured force and acceleration data. In Figure 5 the grid is displayed, where 10 nodes as hitting spots are displayed as circles, and the 3 sensor locations are indicated by the filled circles. In figure 4 the placement of the accelerometers on the beam is shown.

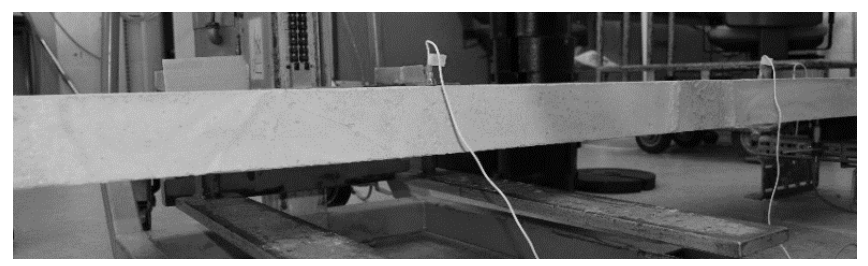

Figure 4. Placement of accelerometers and hitting points 


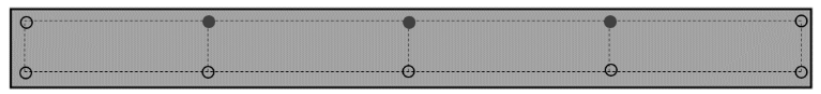

Figure 5. Placement of the accelerometers on the concrete beam

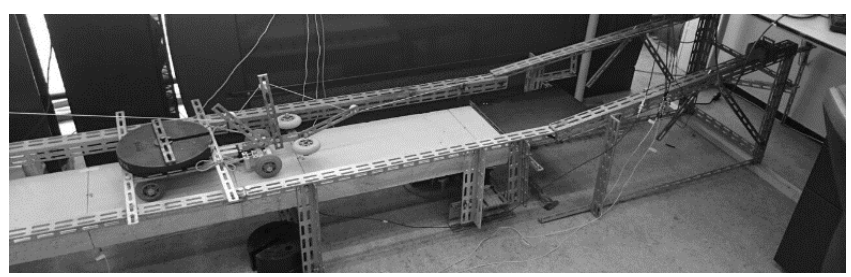

Figure 6. Moving vehicle driving over the concrete beam

In the experiments no. 3,5,7,9 steel weights of each $10 \mathrm{~kg}$ are used. A moving vehicle that is loaded with weights of $10 \mathrm{~kg}$ each is used in experiments no.11,12,13 (see figure 6). The vehicle is kept in balance by a guidance chord and rail to ensure that the vehicle drives straight on the beam. The vehicle itself has an load of $6 \mathrm{~kg}$. The movement of the vehicle is induced by acceleration from a ramp.

\section{LABORATORY EXPERIMENTS ANALYSIS}

The analyses of the laboratory experiments are done with two different methods. The first is called the static analysis that makes use of measurements of the LVDT's. The second one is called the dynamic analysis that makes use of the accelerometer measurements.

\subsection{Static analysis}

The static analysis of the laboratory experiments consists of analysing the static loaded beam experiment and the dynamic (moving vehicle) loaded beam experiment.

\subsubsection{Calibration of the bearing blocks}

Prior to the execution of the laboratory tests a calibration of the bearing blocks (no.1) is done. The purpose of the calibration is finding the stiffness of the bearing blocks that is used for calculating reaction forces out of deflections. To find the bearing block stiffness a load is applied on the concrete beam at the position right above the rubber bearings. The load is applied in steps of $5 \mathrm{~kg}$, increasing to a total load of $50 \mathrm{~kg}$ after $32 \mathrm{sec}$. A bearing stiffness of $380 \mathrm{~N} / \mathrm{mm}$ is obtained from the slope of this curve $(50 \mathrm{~kg} / 1.32 \mathrm{~mm})$. The displacements measured with the LVDT's are shown in figure 7 .

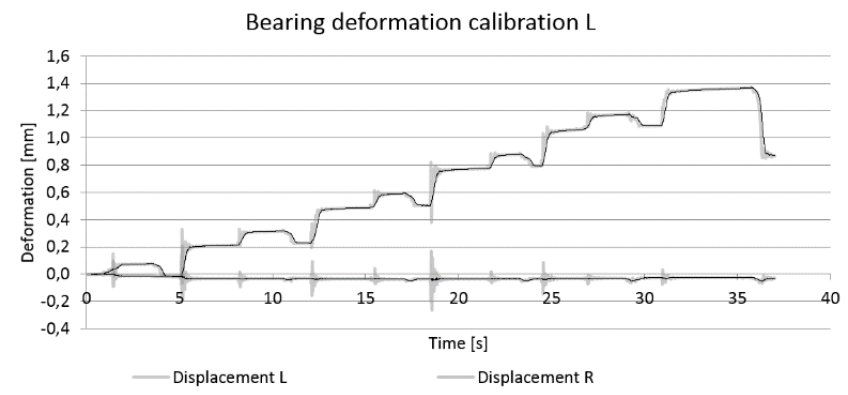

Figure 7. Calibration results of bearing block

\subsubsection{Time dependent behavior of bearing blocks}

The calibration of the bearing blocks is done in a total timespan of $35 \mathrm{sec}$ where roughly each $2.5 \mathrm{sec}$ a change in loading was applied. Here time dependent effects such as creep of the rubber bearing aren't taken into account. Therefore the laboratory experiment TDB (see table 1) is done. In this experiment for $40 \mathrm{sec}$ a weight of $25 \mathrm{~kg}$, and thereafter for also $40 \mathrm{sec}$ a weight of $50 \mathrm{~kg}$ are placed right above the bearing. The difference between the rubber bearing blocks' known linear elastic deformation and the measured nonlinear deformations are plotted (see figure 8), resulting in only the time dependent behavior. Over the measured deformations a logarithmic trend line is added from which an equation for the time dependent behavior is calculated (equation 1). This equation is used in the static analysis in situations where time dependent behavior of the bearing blocks needs to be considered.

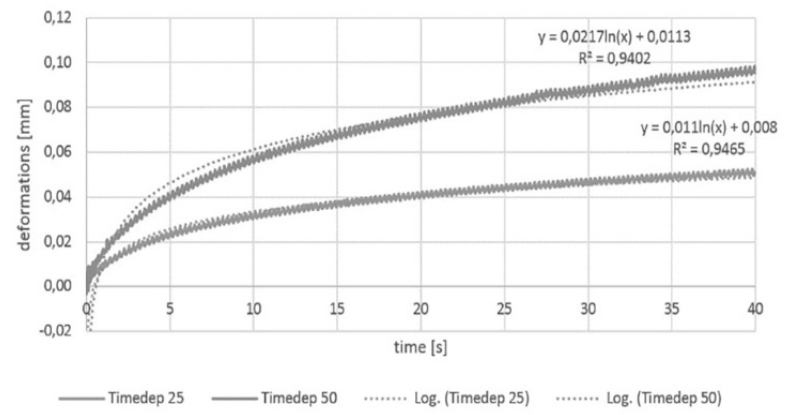

Figure 8 . Time dependent behavior of rubber bearing blocks

The equation for the displacement $u$ as a function of force $F$ and time $T$ is:

$\Delta u=\Delta F \cdot\left(4,49 \cdot 10^{-5} \cdot \ln (\Delta T)+2,13 \cdot 10^{-4}\right)$ 


\subsubsection{Static analysis of statically loaded beam}

In the first static load experiment (no.3) the beam is loaded till $80 \mathrm{~kg}$ in a total time span of $15 \mathrm{sec}$. The load was placed at the mid-span of the beam, and it was denoted that after applying the $80 \mathrm{~kg}$ the first crack occurred. While the beam was loaded, the deformations of the LVDT's and accelerations were recorded. After unloading the $80 \mathrm{~kg}$, the beam was again loaded at the mid-span until more cracks occur. The loading was increased to $120 \mathrm{~kg}$ conform experiment no 4 . After unloading the $120 \mathrm{~kg}$, the next step would be to increase the load to $180 \mathrm{~kg}$. However, stacking up loads till this weight could lead to safety problems regarding the stability of the placed loads. Therefore the choice was made to place two people together weighing approximately $180 \mathrm{~kg}$ at the mid-span of the beam. For curiosity reasons during the $180 \mathrm{~kg}$ loading experiment the two people standing on the beam were exciting the beam by making small jumps. The calculated average deformations of LVDT2 and LVDT3 divided by the distance between the LVDTs $(131 \mathrm{~mm}$, see figure 2) yields the slope of the concrete beam at the supports.

This, combined with the known loading makes that the bending stiffness (EI) of the concrete beam can be calculated with the following equation:

$E I=\left(F L^{2}\right) /(16 \theta \max )$

Here $\theta$ is the slope calculated from the LVDT displacements. The results of the calculated bending stiffness (EI) of the concrete beam under different load levels is shown in figure 9 . This figure shows that the calculated bending stiffness for the experiment no. 3 yields a fuzzy result in the first $7 \mathrm{sec}$. This might be because the test set-up needs to be "set". After this, it can be observed that the concrete beam loses stiffness after crack initiation. An additional loss in stiffness is well noticeable at $20 \mathrm{sec}$ of experiment 4.

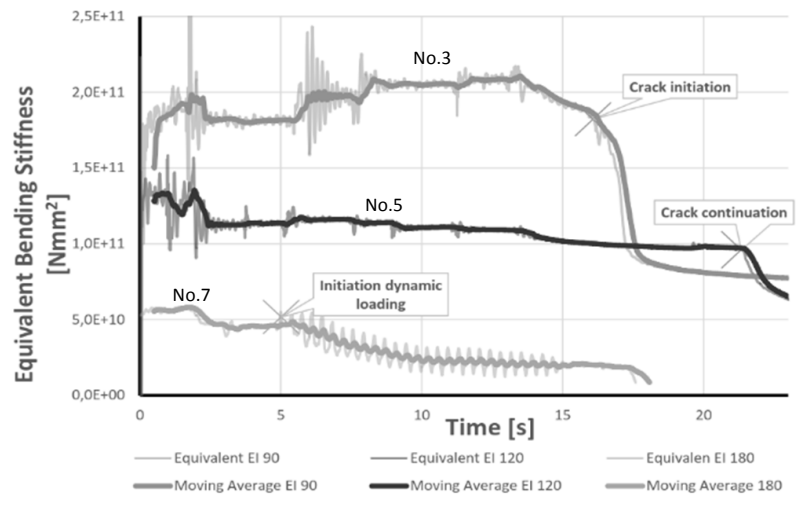

Figure 9. Calculated bending stiffness for static experiments

\subsubsection{Static analysis of dynamically loaded beam}

In the laboratory experiment with a similar load on a new uncracked concrete beam, equal to the one used in the previous experiment, the sensors again are placed at similar positions. At the left side of the beam a wooden ramp is built in order to get the vehicle up to the desired speed by letting the vehicle run off. The speed of the vehicle is adjustable by releasing it from a higher point on the ramp. The vehicle runs from the left end of the beam till the right end of the beam. On the right end of the beam the vehicle breaks by making contact with the guard rail. In between the wooden ramp and the concrete beam a small gap of $5 \mathrm{~mm}$ is present. This makes that a dynamic excitation of the beam is induced.

In the experiments 11,12,13 variations are made in weight of the vehicle, speed of the vehicle and damage level of the beam. During the experiments the deformation of the bearing blocks were measured. The measurements show a clear relation with the movement of the vehicle (see figure 10). First, at $0.6 \mathrm{sec}$. the deformation of LVDT1 (at the left side of the beam) goes up where after it reduces when the vehicle is moving over the beam. After 1.6sec. it is clear that the deformation of the LVDT's is equal meaning that the vehicle is in the middle of the span of the beam. After $3.2 \mathrm{sec}$. the vehicle runs of the beam and no LVDT deformations are measured (figure 10).

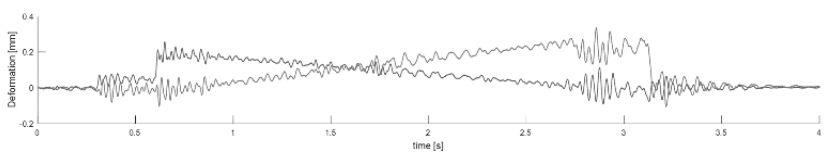

Figure 10. Measured LVDT deformations with moving vehicle

From all the executed experiments with the moving vehicle again a bending stiffness is calculated for the concrete beam under different damage levels. Here, the average calculated bending stiffness for an uncracked beam under various loads and speeds is equal to $2.7 \mathrm{E}+11 \mathrm{Nmm}^{2}$. For damage level 1 (initial cracks) a bending stiffness of $1.5 \mathrm{E}+11 \mathrm{Nmm}^{2}$ and for damage level 2 a bending stiffness of $0.7 \mathrm{E}+11 \mathrm{Nmm}^{2}$ is calculated from the slope of the concrete beam under different load positions.

For making a comparison between the calculated concrete beam bending stiffness values Table 2 has been made. From the data in Table 2 it is observable that the calculated bending stiffness of the concrete beam under different damage levels, loaded with a static or a dynamic load is comparable. 
Table 2. Calculated bending stiffness of concrete beams

\begin{tabular}{lcc}
\hline $\begin{array}{l}\text { Experiment } \\
\text { No. }\end{array}$ & $\begin{array}{c}\text { Bending stiffness } \\
\mathrm{Nmm}^{2}\end{array}$ & $\begin{array}{r}\text { Damage } \\
\text { Level }\end{array}$ \\
\hline Lab.1.Static & $2.1 \mathrm{E}+11$ & 0 \\
Lab.1.Static & $1.4 \mathrm{E}+11$ & 1 \\
Lab.2.Static & $0.6 \mathrm{E}+11$ & 2 \\
Lab.3.Static & $0.2 \mathrm{E}+11$ & 3 \\
Lab.4.Dynamic & $2.7 \mathrm{E}+11$ & 0 \\
Lab.5.Dynamic & $1.5 \mathrm{E}+11$ & 1 \\
Lab.6.Dynamic & $0.7 \mathrm{E}+11$ & 2 \\
\hline
\end{tabular}

\subsection{Dynamic analysis}

The fundamental idea of vibration monitoring can be summarized as the detection of damage-induced changes in the modal parameters of a structure. More clearly, any change in the modal parameters (natural frequency, modal damping and mode shapes) of a structure can be traced back to a variation of physical properties (mass, damping and stiffness) (Fan \& Qiao, 2010).

In this research, in addition to the traditionally used accelerometers, LVDTs have been installed to the structure to measure the dynamic responses. The main objective of the current research is to capture the dynamic response of the structure via LVDTs to take its advantages. Firstly, they are installed at support points, which are more easily accessible than mid-span positions of a bridge (where the accelerometer are typically mounted). Secondly, the dimension of the quantity that is measured via LVDTs is usually in a range $(\mathrm{mm})$ that would be easier to compare with strain gauge measurements $(\mu \varepsilon)$. The acceleration sensors have been used to calculate the dynamic stiffness from the measured natural frequencies and also to investigate how the peaks in the frequency domain are changing due to both damage and variations in the (moving) load. Furthermore, the dynamic deflection at mid-span of the beam will be discussed via LVDTs measurements.

\subsubsection{Impact test}

As a brief recall, experimental modal analysis is a method to determine the modal parameters of a structure with known physical properties. Impact testing is a common procedure to perform experimental modal analysis (Maia, Silva, He, Lieven, Lin, Skingle, To, Urgueira, 1997). The simplest form of a non-periodic forcing function is the unit impulse or Dirac delta function and the response is called the unit impulse response function (IRF). The general dynamic equation and the force function are presented in equations (3-7), where $x(t)$ is the beam deflection, and its $1^{\text {st }}$ and $2^{\text {nd }}$ time-derivative represent the velocity and acceleration. The parameters $m, c$ and $k$ are the mass, stiffness and damping of the structure and $\delta$ represents the Dirac delta function providing an infinitely short duration pulse at $t=\tau$. The response of the structure is then given by equation (6), where $\omega_{n}, \omega_{d}$ and $\xi$ are undamped natural frequency, damped natural frequency and damping ratio respectively. Moreover, $h(t-\tau)$ and $\mathrm{H}(\omega)$ denote the unit impulse response function (IRF) and the system frequency response function (FRF) respectively. Through the latter function, and specifically its complex component, the modal properties can be revealed (Maia, Silva, He, Lieven, Lin, Skingle, To, Urgueira, 1997).

$$
\begin{aligned}
& m \ddot{x}(t)+c \dot{x}(t)+k x(t)=f(t) \\
& f(t)=\delta(t-\tau) \\
& \lim _{\Delta t \rightarrow 0} \int_{-\tau}^{\tau+\Delta t} f(t) d t=1 \\
& h(t-\tau)=e^{-\xi \omega_{n}(t-\tau)} \frac{1}{m \omega_{d}} \sin \left[\omega_{d}(t-\tau)\right] \text { for } t>\tau(6) \\
& \frac{x(t)}{f(t)}=H(\omega)
\end{aligned}
$$

In one of the previous sections, the static load corresponding to the cracking moment was determined to distinct the healthy condition (uncracked) of the beam from the damaged. The notation $\mathrm{P} / \mathrm{G}$ denotes the ratio of the applied load (in terms of the applied mass) to the beam weight, which used as load increment.

A series of impact experiments have been executed for four different conditions of the beam. The first test was on the healthy beam and the other three tests have been done on the beam that was cracked due to increasing loads (see damage levels in Table 1). As can be seen in Figure 11 there is a shift in the natural frequencies of the structure due to the cracking. The analytical formula for the natural frequencies of a simply supported beam is (Fryba, 1997);

$f_{(n)}=\frac{n^{2} \pi}{2 L^{2}} \sqrt{\frac{E I}{\mu}}$

where $E I, L$ and $\mu$ are the beam stiffness, beam length and the mass per unit length of the beam respectively and the mode number is indicated by $n$. Therefore, not only the frequency but also the frequency shift increases with the $2^{\text {nd }}$ power of the mode number. However, the same trend has been revealed for both uncracked and cracked conditions of the beam through experiments. In figure 11 one can 
see the measured frequencies in each step as data points and corresponding fit curves. The fitting

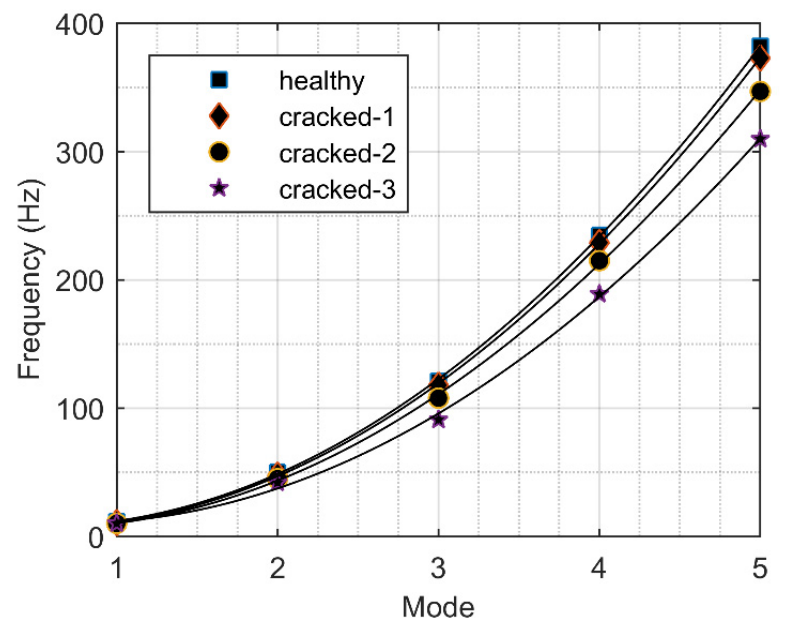

Figure 11. Shift of the first five frequencies as a function of the level of damage

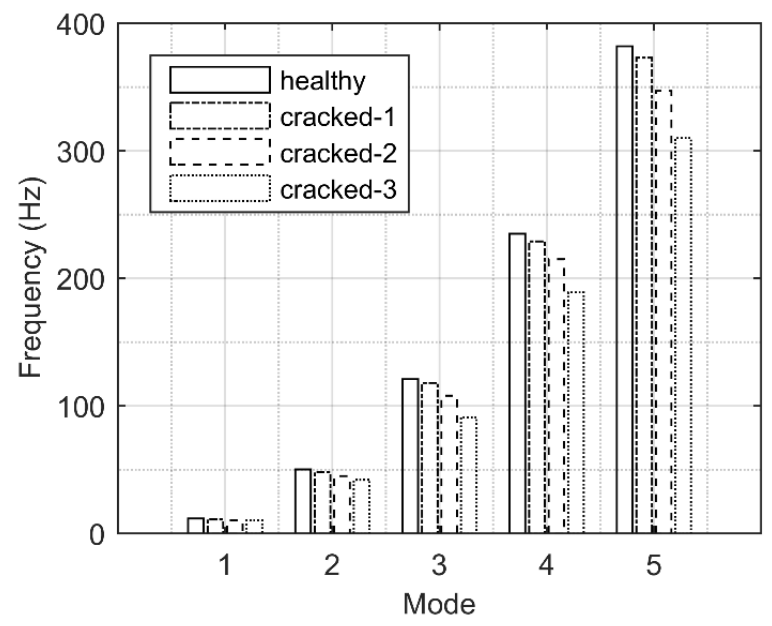

Figure 1. Variation with mode number of the natural frequencies (in $\mathrm{Hz}$ ) for the different damage levels.

curve is a polynomial of degree 2 . Hence, the reduction of the frequencies is higher when the mode number increases, which means the frequency shift due to damage is more sensitive at the higher modes.

In Figure 12, the natural frequencies at the various levels of damage are plotted for the five modes. The relative shift in each step with respect to the previous step can be observed from the slope across the four bars in a group (mode number). This slope is around zero for the first mode and it is increasing (in a negative sense) by increasing mode number.

In (Massenzio, 2005) the first five natural frequencies have been reported for both the intact reinforced concrete beam and the cracked one. The same trend as Figure 12 can be seen through plotting those frequencies.

Doing an impact test on a real bridge is possible by applying a special instrument. Moreover, through this experiment we have learned how the natural frequencies shift while the condition of a structure is changing from uncracked to different levels of cracking.

\subsection{2 moving load}

The bridge vibration due to the passing of a vehicle is in the context of the vibration of solids under moving loads. The model that we called 'FrybaModel" (Fryba, 1997) has been applied as an analytical model to compare with the measurement results. The Fryba model is based on a simply supported Euler-Bernoulli beam with a moving mass, which is assumed to be much smaller than the beam weight (see Figure 13). The velocity of the moving mass is assumed to be constant along the beam. The differential equation and its exact solution can be seen below. This solution corresponds to the boundary condition of the simply supported beam.

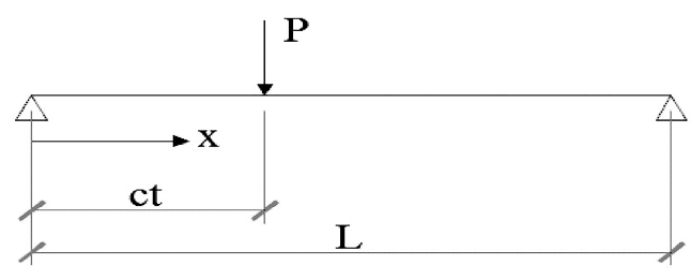

Figure 2. Simply supported beam subjected to a moving force P (Fryba, 1997)

$E I \frac{\partial X^{4}(x, t)}{\partial x^{4}}+\mu \frac{\partial X^{2}(x, t)}{\partial t^{2}}+2 \mu \omega_{b} \frac{\partial X(x, t)}{\partial t}=\delta(x-c t) P$

$X(x, t)=X_{0} \sum_{n=0}^{\infty} \frac{1}{n^{2}\left[n^{2}\left(n^{2}-\alpha^{2}\right)^{2}+4 \alpha^{2} \beta^{2}\right]}$

$\left[n^{2}\left(n^{2}-\alpha^{2}\right) \sin n \omega t-\frac{n \alpha\left[n^{2}\left(n^{2}-\alpha^{2}\right)-2 \beta^{2}\right]}{\left(n^{4}-\beta^{4}\right)^{\frac{1}{2}}} e^{-\omega_{b} t} \sin \omega_{(n)}^{\prime} t-\right.$

$\left.2 n \alpha \beta\left(\cos n \omega t-e^{-\omega_{b} t} \cos \omega_{(n)}^{\prime} t\right)\right] \sin \frac{n \pi x}{L}$

$\omega=\frac{\pi c}{L}$

$\alpha^{2}=\frac{\mu c^{2} L^{2}}{E I \pi^{2}}=\frac{c}{c_{c r}}$

$\boldsymbol{\beta}^{2}=\frac{\mu \omega_{b}^{2} L^{4}}{E I \pi^{4}}$

where $x$ is the length coordinate along the beam, $t$ is time, $X(x, t)$ is the vertical deflection of the beam, $E I$ is the beam stiffness, $\mu$ the mass per unit length, $\omega b$ the angular frequency of damping of the beam, $\omega$ the beam excitation frequency, $P$ the concentrated force, 
$c$ the speed of moving load and $L$ the length of the beam.

This experiment aimed to investigate the effect of mass and speed on the frequency content of the vibration signal obtained from the structure and also on the mid-span displacement. A series of measurements was performed for $10 \mathrm{~kg}, 20 \mathrm{~kg}$ and $30 \mathrm{~kg}$ masses, corresponding to $10 \%, 20 \%$ and $25 \%$ of the beam weight, with speeds of $1 \mathrm{~m} / \mathrm{s}, 1.5 \mathrm{~m} / \mathrm{s}$ and 2 $\mathrm{m} / \mathrm{s}$. This corresponds to the relative weight of a 25 tons truck on a 2 lane bridge with a $25 \mathrm{~m}$ span.

The influence of different mass and velocity has been studied through investigation of the dynamic deflection at mid-span. The beam dynamic deflection at $x=L / 2$ for a $10 \mathrm{~kg}$ moving mass calculated by the equation mentioned above, $X(x, t)$. The curves in figure 14 present $X(L / 2, c t / L)$ for an undamped structure $(\beta=0)$ and for different $\alpha$ values. $\alpha$ is a nondimensional parameter as defined in equation (12). The static case is corresponding to $\alpha=0$ in the equation. The horizontal axis is normalized to the passage time $(c t / L)$. In that way, the curves for different speeds can easily be compared. As can be seen in figure 14, increasing the speed (increasing $\alpha$ ) causes an increase in the displacement.

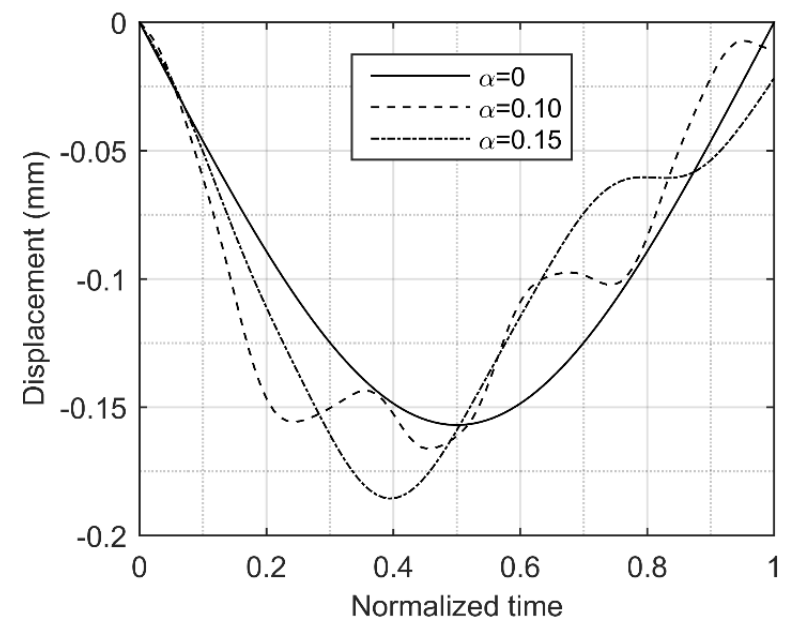

Figure 3. Dynamic deflection at mid-span of the beam for various values of speed

In the experiments the beam slope has been obtained via LVDTs measurements and subsequently mid-span deflection has been captured. The load $P$ indicates the different masses, while the $\alpha$ value indicates the different velocities. The comparison of the experimental and model values is shown in figure 15. The deflected shape has been reconstructed. The displacement of the middle of the beam is obtained by fitting a second order polynomial to the measured LVDT displacements. The measurement results are in good accordance with the model results. The measurements also clearly show that by increasing the velocity the mid-span displacement is increasing. However the rate of increase in the experiments is somewhat lower than the model predicts as can be seen in figure 16 .

In addition to the effect on the defection, the influence of varying the mass is a change of the beam natural frequencies due to the moving mass. In figure 17, the natural frequency predicted by the analytical model and the measured frequency, corresponding to passing different moving loads, are compared.

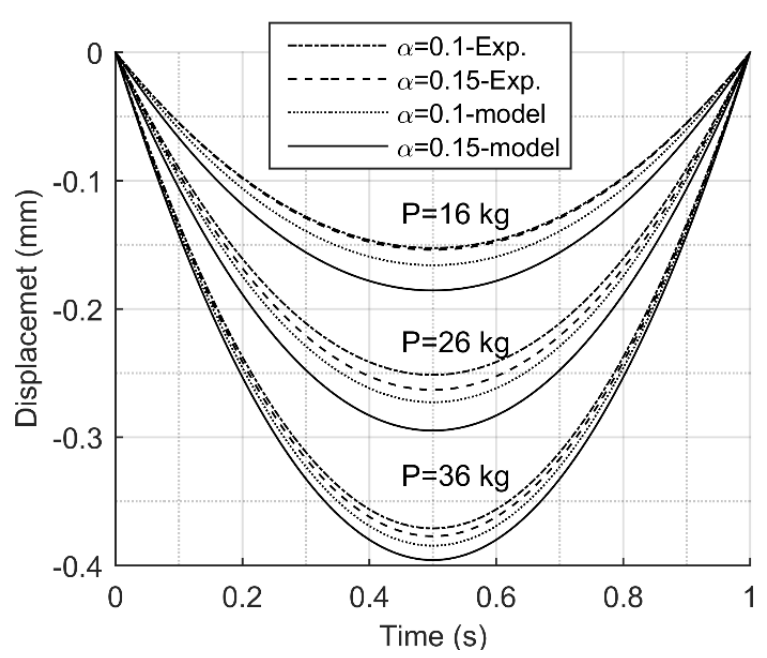

Figure 4. Fitted curves to the mid-span dynamic and static midspan displacement

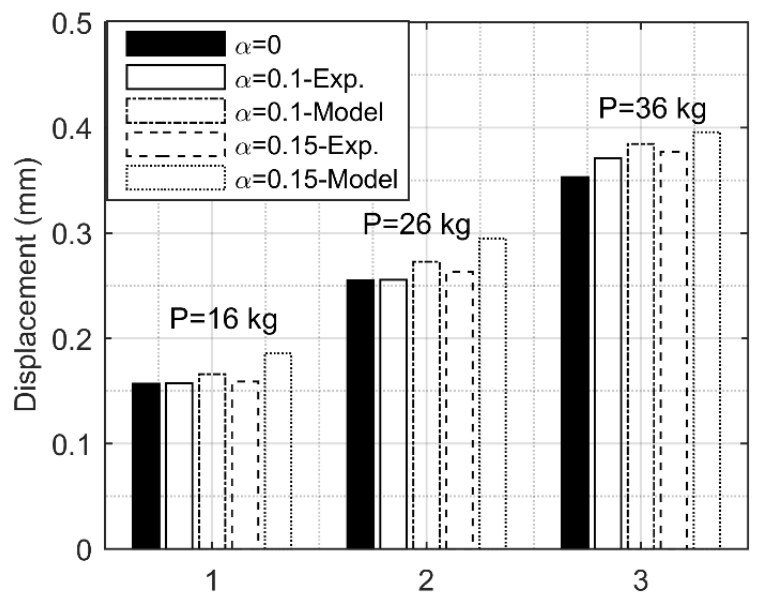

Figure 5. Comparison of the mid-span displacement obtained by model and moving load experiment

The horizontal axis is the percentage of mass to the beam weight $\mathrm{P} / \mathrm{G}$ and the vertical axis is the ratio 
of the structure frequency reduction due to the moving mass. The graph clearly shows a decrease of the first natural frequency due to increase of the mass, in accordance with the theoretical expectations. It justifies the basic assumption of the model, considering the weight to be much smaller than the beam weight to consider it as a moving load.

Subsequently the beam bending stiffness has been obtained through the moving load experiments no. 11,12 and 13. However, based on the previous observations about the effect of the moving mass on the frequency, the bending stiffness has been determined only for the $10 \mathrm{~kg}$ moving mass. The result are displayed in Table 4.

Table 4. Calculated bending stiffness via moving load test

\begin{tabular}{llc}
\hline $\begin{array}{l}\text { Experiment } \\
\text { No. }\end{array}$ & $\begin{array}{c}\text { Bending stiffness (EI) } \\
\text { N.mm }\end{array}$ & $\begin{array}{c}\text { Damage } \\
\text { Level }\end{array}$ \\
\hline 11 & $2.00 \mathrm{E}+11$ & 0 \\
12 & $1.28 \mathrm{E}+11$ & 1 \\
13 & $0.80 \mathrm{E}+11$ & 2 \\
\hline
\end{tabular}

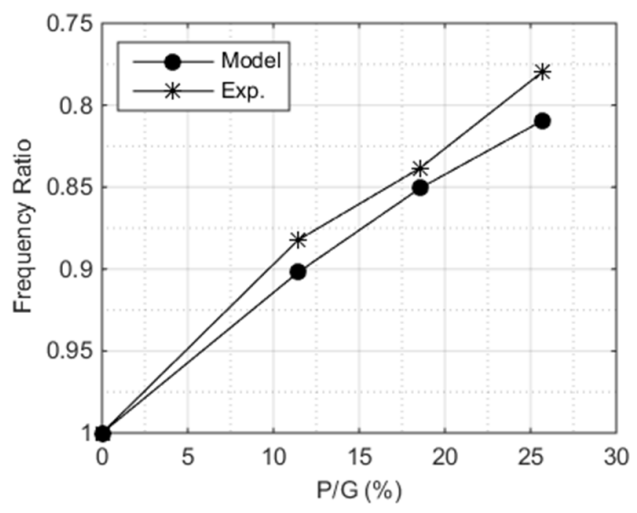

Figure 6. Change of the first natural frequency of the beam due to different moving loads

\section{PILOT PROJECT MAXIMA BRIDGE}

A pilot project is performed at a double track railway bridge located in Rosmalen. A railroad bridge is selected because of the large difference between the loaded and unloaded situation. The bridge consists of a continuous three span prestressed concrete trough beam supported on eight pot bearings (see figure 18).Both LVDT's (displacement) and accelerometers (accelerations) are applied to the bridge deck. Four LVDT's were available for this pilot project. Two were placed at a support at the abutment, and two were placed at the intermediate column. The
LVDTs were placed in front of, and behind the bearings. In total 18 passing trains are measured. Contrary to the laboratory experiments, for many trains the weight, speed and axle distances were unknown.

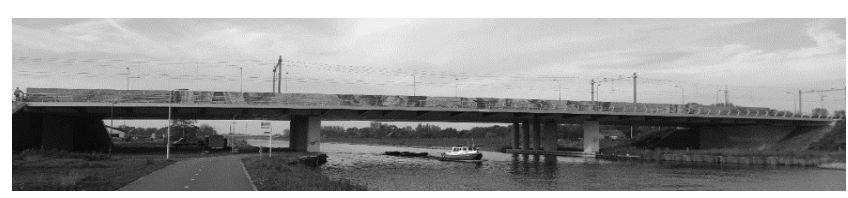

Figure 18. Monitored railway bridge in Rosmalen.

\section{1 static results}

The purpose of the static analysis on the railway bridge is to calculate the bridge bending stiffness under different trains. Therefore the train weight and the response of the bridge under this weight is required. For the static results, data of one LVDT at the abutment side wasn't received due to a defect. This makes that data from one LVDT at the abutment, and two at the intermediate support was used. The measured displacements for a train passing from Den-Bosch to Nijmegen are limited to $0.08 \mathrm{~mm}$ (see figure 19). Observable is that first the LVDT at the abutment measures displacement. After this the two LVDTs at the intermediate support show deformations. The obtained data as shown in figure 19 is used to extract vehicle data. From the measured data it can be observed that a SGM (Stadsgewestelijk Materieel), in Dutch common speech called a "sprinter", consisting of three wagons has passed. This train is travelling in the direction towards Nijmegen.

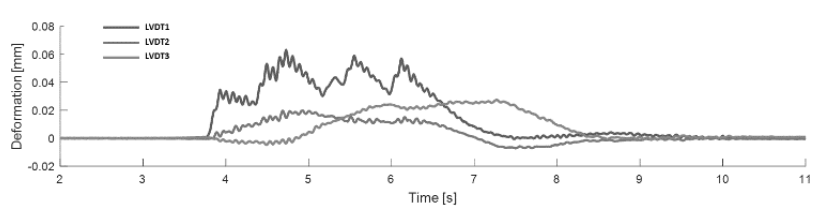

Figure 19. Deformation measurement for a train passing from Den-Bosch to Nijmegen.

To find characteristics of the train, influence lines of the railway bridge are calculated with a finite element model. Here reaction forces are determined for a single point load moving over the bridge (see figure $20)$. When the point load is at the abutment $(x=0)$, the quantity of the reaction force at the abutment with regard to the total load is 1.0. The maximum value of reaction at the intermediate support is when the point load is at position $x=33$. The total length of the railway bridge is $110 \mathrm{~m}$. 


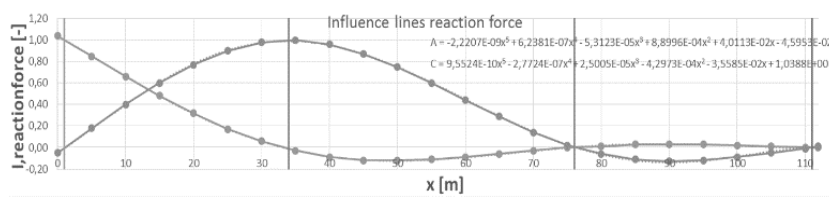

Figure 20. Influence lines for the railway bridge

Since the LVDT data gives only deformation, the bearing stiffness has to be found to calculate train weights. The bearing stiffness is found by using the known weight of locomotives from the 1700 series that are very common on the Dutch railways. These locomotives have a weight of 86 tonnes $(844 \mathrm{kN})$ equally distributed over 2 bogies of 43 tonnes ( 422 $\mathrm{kN}$ ). With the passing of train number 17 (see figure 21) the bearing stiffness is calculated by fitting the quasi static deformation with the measured deformations with the LVDTs. A bearing stiffness of $3000 \mathrm{MN} / \mathrm{m}$ is found to match best.

Now, with the known bearing stiffness and the influence lines a theoretical quasi static deformation can be fit with the actual measured bearing deformations to find axle distances, traveling speed and axle loads of the passing trains (see figure 22).

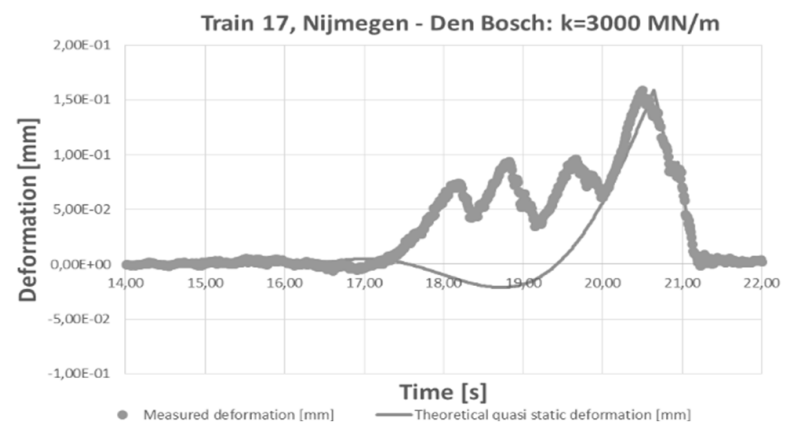

Figure 21. Fitting bearing stiffness on data

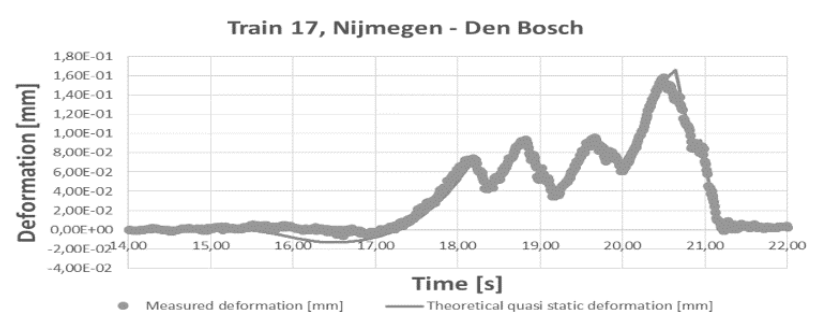

Figure 22. Fitting the theoretical quasi static deformation on the data.
The next step towards calculation of the bending stiffness of the concrete railway bridge was to calculate the bridge slope under a passing train. The bridge slope was determined with the measured LVDT deflections at the mid support. Now, with the same equations as used for the laboratory experiment the bending stiffness of the concrete railway bridge is calculated for in total 18 trains (see figure 23).

For the calculated bending stiffness the best scenario would be to find 18 equal numbers. However, some variation in the calculated bending stiffness is found. This can be explained by one defect LVDT at the abutment that makes that not an average deformation of the bearings is found such as in the laboratory experiment. However, despite the variation, an average stiffness value can now be obtained from the results.

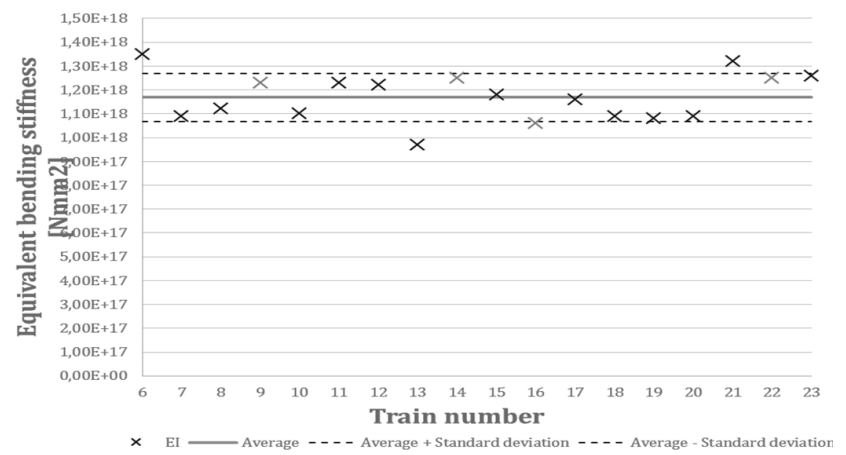

Figure 23. Calculated railway bridge bending stiffness

\section{2 dynamic results}

The instrumentation of the Rosmalen bridge has been done by using LVDTs and accelerometers, similar to the laboratory experiments. A preliminary short field measurement (one day measurement) has been done to validate the measurement system. However, the quality of the measurements via accelerometers was not sufficient due to improper connection of the sensors to the concrete. In the near future a longer measurement will be done on the same bridge. At that occasion, another connection for the accelerometers will be tested.

\section{CONCLUSIONS}

In this research a series of laboratory measurements has been done on the scaled concrete bridge while carrying static and moving loads. Monitoring the change of the bending stiffness of the beam has been done by using LVDTs and accelerometers. The results have been summarized in Table 5 . 
Table 5. Calculated bending stiffness of concrete beams

\begin{tabular}{lccc}
\hline $\begin{array}{l}\text { Experiment } \\
\text { No. }\end{array}$ & $\begin{array}{c}\mathrm{EI}\left(\mathrm{N} / \mathrm{mm}^{2}\right) \\
\text { LVDT }\end{array}$ & $\begin{array}{l}\mathrm{EI}\left(\mathrm{N} / \mathrm{mm}^{2}\right) \\
\text { Accelerometer }\end{array}$ & $\begin{array}{r}\text { damage } \\
\text { level }\end{array}$ \\
\hline 3 & $2.1 \mathrm{E}+11$ & - & 0 \\
4 & - & $2.1 \mathrm{E}+11$ & 0 \\
5 & $1.4 \mathrm{E}+11$ & - & 1 \\
6 & - & $1.9 \mathrm{E}+11$ & 1 \\
7 & $0.6 \mathrm{E}+11$ & - & 2 \\
8 & - & $1.5 \mathrm{E}+11$ & 2 \\
9 & $0.2 \mathrm{E}+11$ & - & 3 \\
10 & - & $1.3 \mathrm{E}+11$ & 3 \\
11 & $2.7 \mathrm{E}+11$ & $2.0 \mathrm{E}+11$ & 0 \\
13 & $1.5 \mathrm{E}+11$ & $1.2 \mathrm{E}+11$ & $2^{*}$ \\
15 & $0.7 \mathrm{E}+11$ & $0.9 \mathrm{E}+11$ & $3^{*}$ \\
\hline
\end{tabular}

Damage level $2 * \& 3 *$ are not exactly the same as $2 \& 3$ since the beam has been replaced after experiment no. 10

As it can be seen in the experiments no. 3 till 10 by increasing the damage level the difference between the obtained EI values from respectively LVDTs and accelerometers is increasing. The reason might be the nonlinear behavior of the concrete beam by increasing cracking level. The EI by LVDT has been determined via an elastic deformation equation of the beam directly, while the EI values calculated from the accelerometer data are obtained via the frequency equation. Therefore, it can be concluded that at least for structures that are not fully damaged, the bending stiffness can be determined by LVDT measurements.

Also by repeating impact tests on the beam with various damage conditions, an overview of the changes in natural frequencies has been acquired for the first five modes. The results show that the frequency shift due to cracking is increasing by increasing the mode number.

The effects of the mass and velocity have been investigated. The outcomes have been compared with the model to confirm that for very small $P / G$ the moving mass can be considered as the constant moving load. Further, the mid-span displacement is decreasing by increasing the velocity.

Regarding the field measurements, the resulting train weights and bending stiffness values determined with each passing train are all within the right order of magnitude. The highest deviation from the average of the 18 measured trains is $15 \%$. More accurate results can be obtained when having all the installed LVDTs working. This may be required for having a more robust system for taking periodic measurements or over short time span. When taking continuous measurements over a longer time span having a deviation of $15 \%$ may yield enough accuracy. Here finding a trend is more important.

\section{FUTURE PROSPECTIVES}

A series of laboratory experiments and also the preliminary field measurement have been done. These measurements have brought promising results to develop the measurement system to monitor the stiffness of the bridge as a degradation criteria. It has been proposed to utilize a camera to remotely monitor the deflection of the structure at the mid-span of the bridge to validate the displacement measurements via LVDTs.

\section{ACKNOWLEDGMENTS}

This work has been performed in the context of the NWO IPPSI KIEM project nr. 628.005.010. The assistance of Z.A.J. Lok in performing the measurements is greatly acknowledged.

\section{REFERENCES}

Cremona, 2014. Assessment of existing structures in France: Standard and advanced practices. s.1., Taylor \& Francis Group.

Fan, W. \& Qiao, P., 2010. Vibration-based Damage Identification Methods: A Review and Comparative Study. SAGE, 10(83-111).

Fryba, L., 1997. vibration of soilids and structures under moving loads. Groningen: Noordhoff International Publishing.

Maia, Silva, He, Lieven, Lin, Skingle, To, Urgueira, 1997. Theoretical and Experimental Modal analysis. New York: JOHN WIELY \& SONS INC..

Massenzio, M. J. E. O. P., 2005. Natural frequency evaluation of a cracked RC beam with or without composite strenthening for a damage assessment. Rilem.

Reitsema, 2015. Towards a SMART Bridge: A Bridge with Self-Monitoring-Analysing, and-Reporting Technologies. Antalya, SMAR2015.

RWS, recieved April 10, 2015. Historical overview year of construction of Dutch bridges in main road network, s.1.: s.n. 